
Aug $1^{\text {st }}, 2015$

Corresponding Author: Prof. John Aplin

Title: Hemangioblastic foci in human first trimester placenta: distribution and gestational profile Authors: Hannah Whittaker, BSc; Stefanie Swietlik, BSc; Jayne C Charnock, PhD; Carolyn J Jones, PhD, DM Manuscript No:PL-15-00053

Dear Graham,

Many thanks for the three constructive reports on our ms. I am now submitting a revised manuscript and illustrations. Below we give our responses to the reviewers, detailing changes we have made, addressing most of the reviewers' suggestions, and pointing out where it has not been practicable. In the revised manuscript, altered sections of text are marked in yellow.

Best wishes

John

Reviewer \#1: This is an interesting manuscript on spatiotemporal expression pattern of hemangioblastic foci in the 1st trimester placenta. Although the reviewer appreciates the remarkable descriptive effort of the authors to characterize blood cell and blood vessel development in early placental tissue some aspects of the work need - in his opinion -clarification.

In reviewer's opinion following questions remain unanswered:

1. Do the HAF cells originate from common bipotent progenitor (hemangioblas?) or different, independently fated mesodermal progenitors or even hemogenic endothelium?

2. Since HAF possibly consist of mixed cell population, further characterisation (using specific markers including FLK-1, Gata-1, CKIt, VE-cadherin or Runx 1) might provide more detailed information in regard to their origin.

3. Do the HAF cells originate from chorionic or allantoic mesoderm?

4. Are HAF cells involved in primitive or definitive hematopoiesis?

We thank the reviewer for these insightful comments. We agree that important questions regarding the origins and fates available to cells in placental HAFs remain unanswered at this stage. Especially given the restrictions associated with working in human, we believe that answers to 1 and 4 will only be gained by carrying out in vitro studies, ideally on very early tissues which are a scarce resource. We aim to develop methods for cell isolation and propagation, but this will take time.

On point 2, several of the markers listed are expressed not only on hemangioblastic cells but also in other placental populations, limiting their use in whole mount imaging studies. However we have added a new stem cell marker, CD41, to the data presented. Its presence in cells emerging from HAFs suggests that non-erythroid fates may be accessible. We have also added some colocalisation data that allow a more detailed insight into the segregation of CD34 (stem cells and endothelial cells) 
from CD235a (erythroid cells). This has required the addition of a new coauthor as well as a larger sample set.

As for point 3, there is evidence of hematopoiesis in the human yolk sac between 16 and 19 days gestation (Kelemen e et al 1979. Atlas of human hematopoietic development. Springer, Berlin) and it has been identified by one of us in the human yolk sac between 6 and 10 weeks (Jones $\mathrm{CJ}$ and Jauniaux E 1995. Micron 26: 145). It is therefore possible that it occurs in the two sites simultaneously.

5. The author's proposal that HAFS may act as oxygen reservoir during early placental development is exciting but not sufficiently supported by the data presented.

We agree this is speculative and have changed the wording in the abstract and text to make it clear.

Reviewer \#2: This manuscript describes the identification and characterisation of what the authors designate as Hemangioblastic foci (HAF). Understanding the processes of vasculogenesis and hematopoeisis in the placenta is both challenging and important. The main challenge is obtaining suitable well preserved specimens. The authors in this study have overcome this by using some newly collected material and archival material. By the nature of such specimens the experimental design is quite constrained and essentially limited to descriptive histological methods. That said, this study is well conducted and my comments will only require modest changes to the manuscript.

We thank this referee for her or his positive remarks.

1 In the abstract (line 40) the authors "propose" that the HAFs (although in the discussion, line 267 that it is the erythrocytes) act as an oxygen reservoir. Thus is all rather speculative and stated a little too strongly. While it is a reasonable speculation I would suggest removing this from the abstract.

See response to referee 1 point 5. We have tried to be more precise in the revised text.

2 The annotation of the figures needs improving. The addition of arrows and indicating in the legend what the arrows that are present are highlighting. At present this is inconsistent.

We've added arrows and asterisks to Figure 2,3,6, annotated the new supplementary figures, and alluded to the corresponding features in the legends.

3 In the methods section the specific biotinylated lectins used are not described. Now addressed.

$4 \quad$ Line 140, the type, not just the degree of glycosylation could also have changed. We agree, now addressed.

$5 \quad$ The section on the proposed role of the hofbauer cells (around line 218) is somewhat speculative and needs to be shortened and phrased with less certainty. The results show very few examples of staining for macrophages and this is in contrast to the disproportionately long section in the discussion. 
We have added some later tissue specimens, extending the study to 11 weeks, and added a new supplementary figure that describes the occurrence of Hofbauer cells in the vicinity of extravascular erythrocytes.

Lines 255-257. This sentence is unclear and should be reworded.

Done.

The Centre for Trophoblast Research (CTR, fig 2) needs to be defined in the methods. Done.

$8 \quad$ Fig 6 - the legend states panels $C$ and $d$ are serial sections. This is not the case in the figure.

This error has been corrected to $A$ and $B$.

Reviewer \#3: Aplin and colleagues describe hemangioblastic foci in human first trimester placenta. The study appears to have been well done using conventional methods.

There are, however, some minor points that need to be addressed.

In Fig. 2, addition of arrows (or some other labeling symbol) to indicate the features mentioned in the text are needed.

Done

In Fig. 3A-C, addition of arrows is needed.

Done

In the legend for Fig. 5, more information is needed for readers to understand what is being shown is needed.

Arrows and asterisks now supplied along with some descriptive text in the legend.

In Fig. 5, the structures of interest should be noted. Also it is not clear why grey scale images are mixed with color images.

Capture was with a monochrome camera, the grey scale images are shown so readers understand that $C$ and $D$ are false colour images.

The legend for Fig. 6 is so brief that it provides little information. For example, what are the labeled structures? Again, labeling the figures would be helpful.

Labels added.

In the Discussion, the authors point out that improper fixation may have been a problem in some studies related to this topic. Surprisingly, the fixation conditions for this study were not given (except for the glutaraldehyde used for the resin embedded specimens).

Now addressed.

In the Abstract (Methods), it is stated that thin sections were used. Generally the term "thin section" is used to describe resin embedded samples that are sectioned at 50-100 nm for examination by transmission electron microscopy. The wording should be modified.

Now given as semi-thin. 
While the sources of antibodies and their concentrations were given, this is not the case for the lectins. This information is needed.

Now given.

What are the binding partners for the two lectins used in this study? Why were these lectins used and not some other lectins.

Explanation provided. 


\section{Author statement}

We wish to confirm that there are no known conflicts of interest associated with this publication and there has been no significant financial support for this work that could have influenced its outcome.

We confirm that the manuscript has been read and approved by all named authors and that there are no other persons who satisfied the criteria for authorship but are not listed. We further confirm that the order of authors listed in the manuscript has been approved by all of us.

We confirm that we have given due consideration to the protection of intellectual property associated with this work and that there are no impediments to publication, including the timing of publication, with respect to intellectual property. In so doing we confirm that we have followed the regulations of our institutions concerning intellectual property.

We further confirm that any aspert of the work covered in this manuscript that has involved either human patients has been conducted with the ethical approval of all relevant bodies and that such approvals are acknowledged within the manuscript.

We understand that the Corresponding Author is the sole contact for the Editorial process fincluding Editorial Manager and direct communications with the office). He is responsible for communicating with the other authors about progress, submissions of revisions and flinal approval of proofs. We confirm that we have provided a current, correct email address which is accessible by the Corresponding Author and which has been configured to accept email from johin.aplin@machester:ac.uk

Signed by all authors as follows:

John Aplin

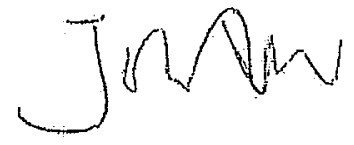

Hannah Whittaker

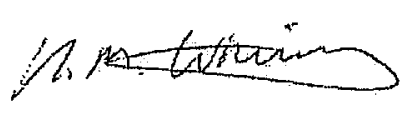

Stefanie Swietlik

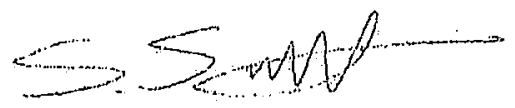

Jayne Charnock

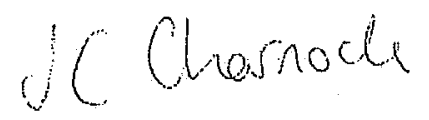

Carolyn Jones

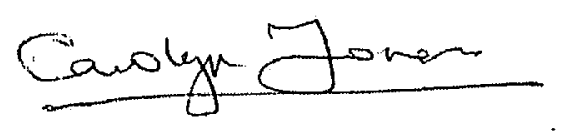


1 Hemangioblastic foci in human first trimester placenta: distribution and gestational profile

2

3

John D Aplin, Hannah Whittaker, Yu Ting Jana Lim, Stefanie Swietlik, Jayne Charnock and Carolyn JP

4 Jones

5

6 Maternal and Fetal Health Centre, Institute of Human Development, University of Manchester, St.

7 Mary's Hospital, Central Manchester University Hospitals NHS Foundation Trust, Manchester

8 Academic Health Science Centre, Manchester M13 9WL.

9

10 Address for correspondence: John Aplin, Maternal and Fetal Health Centre, St Mary's Hospital,

11 Manchester M13 9WL

12

13 Key words: placenta, human, first trimester, stem cell, hematopoiesis, erythroid, vasculogenesis,

14 endothelium, hemangioblast

15 
Introduction: The human placenta is a site of both hematopoiesis and vasculogenesis. There are reports of hemangioblastic foci (HAF) in the first trimester placenta, but little published information about their spatiotemporal incidence.

Methods: We have used semi-thin sections and whole mount staining techniques on archival early pregnancy hysterectomy material as well as freshly-collected termination tissue.

Results: We report a description of the distribution of $\mathrm{HAF}$, their gestational profile, and some characteristics of the constituent cells. We show crypt-shaped HAF are present in villi at different levels from 4-11 weeks and in the chorionic plate from 4-9 weeks. In the villous placenta, the foci often approach closely at one end to the trophoblast basement membrane. Morphologically they show remarkable similarity to those found in the yolk sac at similar stages. In some crypts, all cells are CD34+, but CD34 and nestin progressively segregate into the endothelial lineage. Brachyury is present in less differentiated cells. The erythroid lineage is dominant, as shown by the widespread expression of CD235a/glycophorin and characteristic erythroid morphologies, indicating various degrees of differentiation. However, CD41 is also present in non-endothelial cells. Initially a discontinuous UEA-1/CD31-positive endothelium forms at the periphery of the foci. These cells appear to become integrated into the developing vasculogenic/angiogenic vessel network. We also demonstrate that, independent of HAF, vasculogenesis occurs near the tips of growing villi during the first trimester.

Discussion: We suggest HAF interface with the developing vascular network, producing communication channels that allow erythrocytes to enter the placental-embryonic circulation. We speculate that the erythroid cells act as oxygen reservoirs during the period before flow of maternal blood through the intervillous space of the placenta, allowing a slow feed of oxygen-rich cells to the developing embryo. 


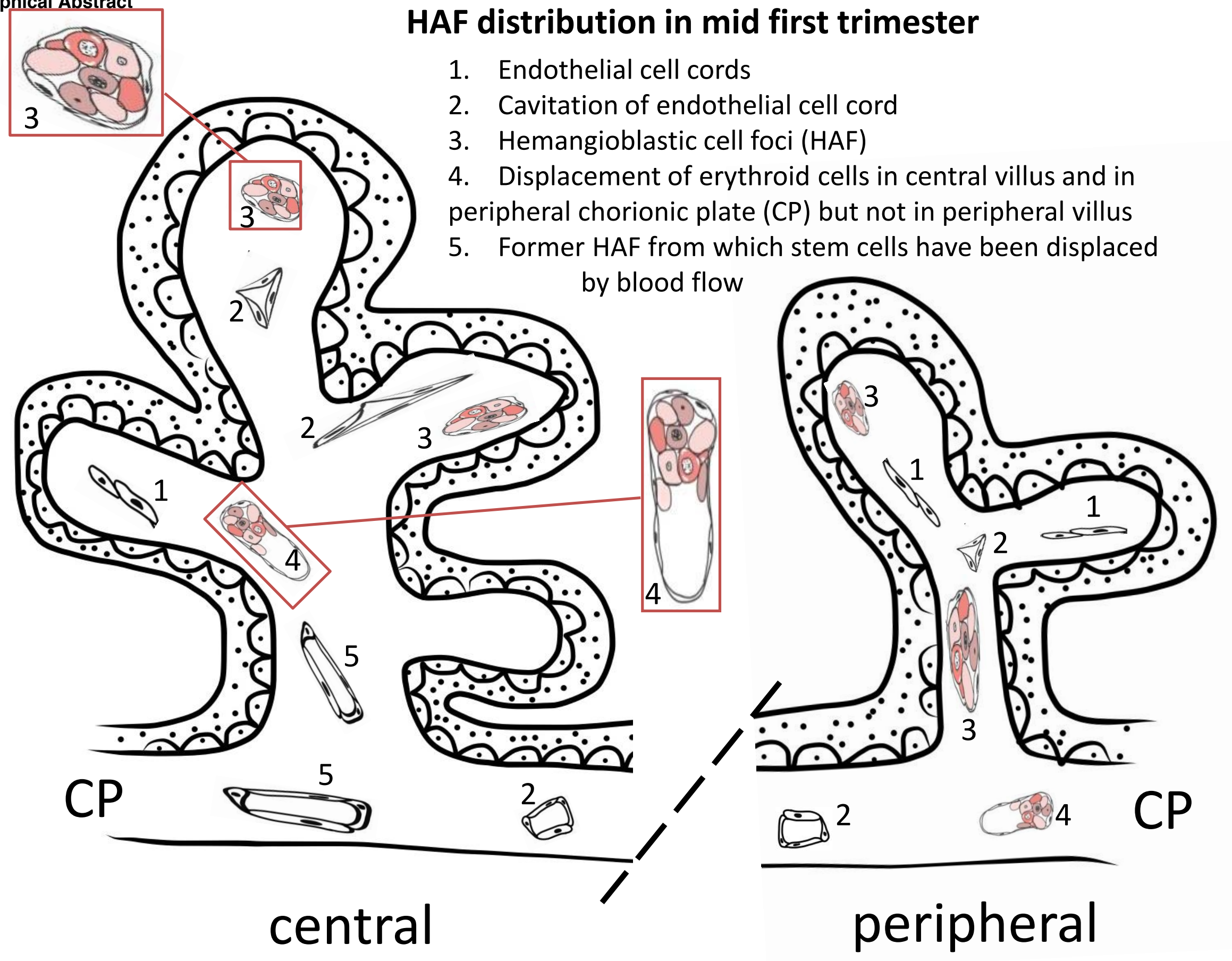




\section{Highlights}

Hematopoiesis occurs in the early human placenta.

We identify hemangioblastic foci distributed randomly through the villous tree and chorionic plate in placenta up to 9-10 weeks.

These are mainly sites of erythropoiesis, surrounded by a progressively developing endothelium.

We propose that oxygen-loaded red cells are released gradually from these sites as the embryonic circulation spreads through the chorionic plate and into distal regions of the villous tree.

We show that vasculogenesis continues during first trimester at growing villous tips. Such sites are unrelated to hemangioblastic foci, suggesting two distinct endothelial lineages. 
1 Hemangioblastic foci in human first trimester placenta: distribution and gestational profile

2

John D Aplin, Hannah Whittaker, Yu Ting Jana Lim, Stefanie Swietlik, Jayne Charnock and Carolyn JP

4 Jones

5

6

Maternal and Fetal Health Centre, Institute of Human Development, University of Manchester, St.

7

Mary's Hospital, Central Manchester University Hospitals NHS Foundation Trust, Manchester

8 Academic Health Science Centre, Manchester M13 9WL.

9

10 Address for correspondence: John Aplin, Maternal and Fetal Health Centre, St Mary's Hospital,

11 Manchester M13 9WL

12

13 Key words: placenta, human, first trimester, stem cell, hematopoiesis, erythroid, vasculogenesis,

14 endothelium, hemangioblast 
Introduction: The human placenta is a site of both hematopoiesis and vasculogenesis. There are reports of hemangioblastic foci (HAF) in the first trimester placenta, but little published information about their spatiotemporal incidence.

Methods: We have used semi-thin sections and whole mount staining techniques on archival early pregnancy hysterectomy material as well as freshly-collected termination tissue.

Results: We report a description of the distribution of $\mathrm{HAF}$, their gestational profile, and some characteristics of the constituent cells. We show crypt-shaped HAF are present in villi at different levels from 4-11 weeks and in the chorionic plate from 4-9 weeks. In the villous placenta, the foci often approach closely at one end to the trophoblast basement membrane. Morphologically they show remarkable similarity to those found in the yolk sac at similar stages. In some crypts, all cells are CD34+, but CD34 and nestin progressively segregate into the endothelial lineage. Brachyury is present in less differentiated cells. The erythroid lineage is dominant, as shown by the widespread expression of CD235a/glycophorin and characteristic erythroid morphologies, indicating various degrees of differentiation. However, CD41 is also present in non-endothelial cells. Initially a discontinuous UEA-1/CD31-positive endothelium forms at the periphery of the foci. These cells appear to become integrated into the developing vasculogenic/angiogenic vessel network. We also demonstrate that, independent of HAF, vasculogenesis occurs near the tips of growing villi during the first trimester.

Discussion: We suggest HAF interface with the developing vascular network, producing communication channels that allow erythrocytes to enter the placental-embryonic circulation. We speculate that the erythroid cells act as oxygen reservoirs during the period before flow of maternal blood through the intervillous space of the placenta, allowing a slow feed of oxygen-rich cells to the developing embryo. 
In the second week of gestation, the outer trophoblast layers of the implanted human embryo are invested by radial tongues of outgrowing extraembryonic mesenchyme. From day 14 post conception, vascular elements begin to form within this layer, comprising cords of endothelial cells that develop into networks [1-3]. The vascularised mesenchyme forms the stroma of the chorionic plate and, through progressive outgrowth, the core of the rapidly branching and growing villous placenta. The developing placental vascular network connects though the body stalk to the gut, the developing anterior vascular plexus, the heart and yolk sac [1]. Early in the $5^{\text {th }}$ week of gestation, when the heart starts beating, the placental vascular network is connected to the embryo and yolk sac via the chorionic plate and umbilical cord.

Though early studies of the placenta identified vascular elements at these stages [4], limitations in tissue preservation in the mid $20^{\text {th }}$ century probably obscured hemangioblastic and/or hematopoietic activity. This was however suggested in the 1980s [5], and morphological studies as well as in situ cell marker evidence later emerged to support the idea that hemangioblastic sites are present in first trimester placenta [6] as well as in the yolk sac [7]. These sites comprise tightly packed cells, often with recognisable endothelialised margins.

More recently, colony-forming assays conducted with cells isolated from placenta have confirmed the presence of hematopoietic cells both in the first trimester and later in gestation [8]. The relative incidence of the various derivative lineages changes, with erythroid precursor cells dominating in the first 9 weeks though multilineage precursors are also present [9]. Similarly in the mouse, it is clear that in addition to the yolk sac, the placenta proper is an important hematopoietic tissue $[10,11]$.

Late in the first trimester, villi regress over the superficial (capsular) aspect of the placenta and the chorionic plate develops into the avascular chorion laeve. Studies conducted to date have not always enjoyed access to well preserved tissue from a spectrum of early gestational ages, and 
generally have not addressed the question of where and when angioblastic sites are found in relation to the cord insertion. They have also not clarified the spatial and developmental relationships between developing vasculogeneic and angiogenic structures and the primitive cell populations present in putative hemangioblastic foci. Here we have combined various imaging methods, including whole mount immunofluorescence and semithin resin sections, in order to throw light on these and related questions.

\section{Materials and methods}

\subsection{Tissue}

Thirty specimens were analysed from the Manchester early pregnancy tissue bank and 18 from the Boyd collection at the Centre for Trophoblast Research (CTR) at the University of Cambridge. Pregnancy termination tissue 4-12 weeks gestation was Carnegie-staged. Boyd tissues are staged by crown-rump length; these have been converted to an estimated gestational age to the nearest week. Two specimens were also obtained from Dr C Dunk, Toronto. Tissues were cleaned in Dulbecco's Minimal Essential Medium, then fixed in ice-cold 90\% methanol overnight before rehydrating in PBS for whole mount staining. For immunoperoxidase staining, tissue was fixed in neutral buffered formalin overnight then washed and processed into paraffin wax. Efforts were made to minimise the time between collection and fixation. A period of $<4 \mathrm{~h}$ gave acceptable histological preservation.

Whole mount immunofluorescence was carried out essentially as described [12] using directly conjugated monoclonal antibodies to CD235a (Alexa 488 conjugate, BD Pharmingen 559943, 1/200), CD41 (Alexa 488 conjugate, MEM-06, AbCam, 1/50) or CD31 (Alexa 647 conjugate, WM59, BioLegend, San Diego, CA, 1/40).

\subsection{Immunohistochemistry}


Sections $(6 \mu \mathrm{m})$ were heated at $60^{\circ} \mathrm{C}$ for 20 minutes to soften the wax then deparaffinised in Histoclear ( $3 \times 5$ minutes) and rehydrated in alcohol (100\% ethanol $2 \times 3$ minutes, $70 \%$ alcohol 3minutes) then water. They were microwaved $(10 \mathrm{~min})$ in citrate buffer $\mathrm{pH} 6.0(0.01 \mathrm{M})$, cooled for 20 minutes then endogenous peroxidise activity was blocked using $400 \mathrm{ml}$ of methanol containing $1.6 \mathrm{ml} 1 \mathrm{M} \mathrm{HCl} /$ litre with $2 \mathrm{ml} \mathrm{H}_{2} \mathrm{O}_{2}$. After rinsing in running water and TBS a $5 \%$ bovine serum albumin protein block was applied. The sections were incubated overnight at $4^{\circ} \mathrm{C}$ with primary antibodies: monoclonal mouse anti-CD34 (Dako, QBend10, 0.18 $\mu \mathrm{g} / \mathrm{ml}$ ), monoclonal mouse anti-nestin

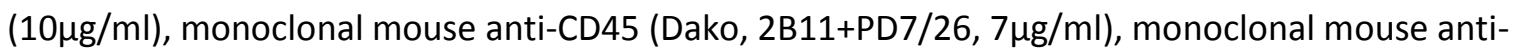

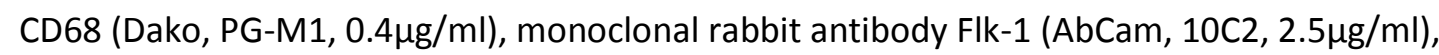
polyclonal goat anti-brachyury (Santa Cruz, C-19, $4 \mu \mathrm{g} / \mathrm{ml}, 2 \mu \mathrm{g} / \mathrm{ml}, 1 \mu \mathrm{g} / \mathrm{ml}$ ). Controls: mouse IgG $(10 \mu \mathrm{g} / \mathrm{ml})$ for nestin and CD34, mouse lgG $(7 \mu \mathrm{m} / \mathrm{ml})$ for CD41, CD45 and CD68, rabbit lgG $(2.5 \mu \mathrm{g} / \mathrm{ml})$ for FLk-1 and TBS (0.125M) for Brachyury. Sections were incubated with secondary antibody: polyclonal goat anti mouse, polyclonal swine anti rabbit or polyclonal rabbit anti goat followed by avidin peroxidise $(5 \mu \mathrm{g} / \mathrm{ml}$ in $0.125 \mathrm{TBS})$. Peroxidise activity was visualized by application of diaminobenzidine. The tissue sections were then washed with TBS (0.125M) and counterstained with hematoxylin. Finally the tissue was dehydrated in alcohol (70\% 3minutes, 100\% 2x 3 minutes) and then cleared in histoclear and mounted in DPX.

\subsection{Semithin sections and lectin histochemistry}

Specimens of placenta of 4, 6, 7 and 8 weeks' gestation and a 6 week yolk sac were fixed in $2.5 \%$ glutaraldehyde in $0.1 \mathrm{M}$ sodium cacodylate buffer $\mathrm{pH} 7.3$ for $4 \mathrm{~h}$, then washed in buffer containing $3 \mathrm{mM}$ calcium chloride several times over $24 \mathrm{~h}$ before being dehydrated and embedded in TAAB epoxy resin (TAAB Laboratory Equipment Ltd., Aldermaston, UK). Sections $0.5 \mu \mathrm{m}$ thick were cut and stained with $1 \%$ toluidine blue in $1 \%$ borax for $2 \mathrm{~min}$ on a hotplate at $60^{\circ} \mathrm{C}$ then rinsed in water. Suitable areas were selected for lectin histochemistry and $0.75 \mu \mathrm{m}$ thick sections were mounted on 3-aminopropyltriethoxysilane-coated slides and dried at $50^{\circ} \mathrm{C}$ for 48 hours after which they were 

europaeus-1, Solarnum tuberosum, Phytolacca americana, Maackia amurensis (all from Vector Laboratories Ltd, Peterborough, UK) and Sambucus nigra-1 (E-Y Laboratories, San Mateo, CA, USA) which bind to fucose (UEA-1), $\mathrm{N}$-acetyl glucosamine oligomers (STA, PAA), $\alpha 2,3$ sialic acid (MAA)and $\alpha 2,6-$ sialic acid (SNA-1). These lectins were selected from a panel of 25 as a previous study (Jones et al., 2015) had indicated that they show binding to cells of the erythroid lineage. Briefly, after resin removal with $50 \%$ sodium ethoxide, blocking endogenous peroxidase and subjecting the sections to a brief trypsinization step, sections were stained with $10 \mu \mathrm{g} / \mathrm{ml}$ (UEA-1, STA, PAA, MAA) or $50 \mu \mathrm{g} / \mathrm{ml}$ (SNA-1) biotinylated lectin in $0.05 \mathrm{M} \mathrm{TBS}$ pH 7.6 with $1 \mathrm{mM}$ added calcium chloride for 1 hour at $37^{\circ} \mathrm{C}$ then treated with $5 \mu \mathrm{g} / \mathrm{ml}$ avidin peroxidase (Sigma) in $0.125 \mathrm{M} \mathrm{TBS}, \mathrm{pH} 7.6$, with $0.347 \mathrm{M}$ sodium chloride for $1 \mathrm{~h}$ at $37^{\circ} \mathrm{C}$ [14]. Sites of lectin binding were revealed with $0.05 \%$ diaminobenzidine tetrahydrochloride dihydrate (Sigma) in 0.05 M TBS, pH 7.6, and 0.015\% hydrogen peroxide (100 volumes) for $5 \mathrm{~min}$ at room temperature. Sections were rinsed then lightly counterstained with Harris's hematoxylin before mounting in DPX. Images were captured on an Olympus microscope using Image-ProPlus software (Media Cybernetics, Rockville, MD, USA).

\section{Results}

\subsection{Morphology and glycosylation of HAF}

Flat-mounted unfixed specimens of first trimester villous placenta from the end of the first month

(Figure 1) showed elongated haemoglobin-rich structures, often with bulbous tips approaching close to, or in direct contact with, the trophoblast basement membrane, though not in all villi. They appeared to connect to channels lacking visible haemoglobin that continued along the axis of the villi. 
Histological wax and semi-thin resin sections of tissue fixed soon after delivery revealed prominent cleft-shaped or ellipsoid structures in the villous mesenchyme alongside small open vessel profiles (Figures 2, 3), sometimes called 'blood islands', here referred to as hemangioblastic foci (HAF), interacting closely with basal cytotrophoblast (Figure 3). In some sections the clefts were seen to comprise branching networks in villous mesenchyme (Figure 2A). Simple open endothelialised vascular channels were also seen, sometimes in close proximity to HAF (Figure $2 \mathrm{C}$ ), both in villi and chorionic plate (CP). Cells packed tightly in the foci showed various stages of erythroid differentiation, with darker and paler Toluidine blue-staining cytoplasm, indicating alterations in organelles and cytoplasmic differentiation. Nuclear profiles varied in diameter, and some cells showed anuclear profiles (Figure 3B), but serial sectioning revealed that most cells are in fact nucleated (Supplemental Figure 1) with variation in nuclear size and chromatin density.

Different staining densities reflecting various degrees and types of cytoplasmic glycosylation could be distinguished in the luminal cells with STA (Figure 3C), MAA and SNA-1, again suggesting cell differentiation. Most cells bound these lectins at the plasma membrane. At 4-6 weeks the luminal cells were often tightly adherent both to the tissue wall, the presumptive endothelium and to one another. From 6-8 weeks more clefts were seen containing cells in a looser arrangement, often at one end of the cleft. Nucleated erythroblasts and some pyrenocytes were found in stroma surrounding HAF, often in groups with Hofbauer cells in the near vicinity, and this occurred more at later stages (9-11 weeks) when the associated vascular spaces contained looser cell aggregates (Figure $4 \mathrm{~F}, \mathrm{G}$ ). Within the HAF, endothelial differentiation was evident; UEA-1, which detects endothelial cells in 157 placenta of all gestations [15], was able to differentiate monolayered endothelial cells exhibiting a flattened shape at the margins of the clefts (Figure 3E,F). A few adjacent cells, not yet incorporated into the presumptive vessel wall, also exhibited UEA-1 staining. Gaps in the UEA-1-positive layer persisted in some locations up to 8 weeks, potentially allowing access of cells to or from the 
surrounding stromal compartment. Consistent with this, histological staining for microfibrillar matrix (reticulin) revealed what appeared to be a discontinuous structure around the developing HAF (Figure 3D). Yolk sac specimens from the same range of gestational ages showed remarkably similar features (Figure 3G,H,I). Biochemical heterogeneity of endothelial cells, which may also be related to the degree of differentiation, was revealed in early pregnancy by variation in binding of PAA (Figure 3J).

\subsection{Gestational profile of HAF}

From 4 weeks, HAF were prominent in the chorionic plate $(\mathrm{CP})$ and major villi (Figure $2 \mathrm{~A}$ and $3 \mathrm{D}$ ) and at 6 weeks particularly large foci were seen in stem villi near sites where they branched from the plate (Figure 4A). By this time all vessels in the central CP were opening (Figure 4B) while in the peripheral CP tightly packed HAF were still present (Figure 4C). Opened lumena were mostly oriented towards the chorionic plate with residual adherent cells in the opposite pole of the clefts (Figure 4A,B). More loosely packed profiles were present in some villi from the earliest stage studied (4 weeks) and they coexisted with close-packed HAF up to 8 weeks, the latter being found increasingly towards the distal part of the villous tree, especially centrally. Distally and laterally, away from the central villous placenta, some villi were present that lacked vessel profiles with lumena of any kind.

From 7 weeks, increasing numbers of discoid, apparently anuclear erythrocytes were present in villous vessel profiles (Fig 4D, E), and spaces had opened up in many HAF (presumably following cell displacement) to leave endothelialised vessels with primitive cells still adherent to the walls. though often containing non-adherent nucleated or anuclear erythrocytes. 
186

187

Immunofluorescence colocalisation was carried out in whole mounted villous tissue using antibodies to CD31 and CD235a. Strong CD235a (glycophorin A) immunoreactivity was evident in ellipsoid structures adjacent to the trophoblast (Figure $5 \mathrm{~A}, \mathrm{E})$. These foci, interpreted as HAF, were present from 5 weeks (the earliest tissue studied using this technique) in the CP and at all levels of the villous tree. They were absent from some villous branches, apparently at random.

Staining of whole-mounted tissue with antibody to CD31 (Figure 5F, Supplemental Figure 2) or CD34 (Supplemental Figures 3,4) revealed an extensive developing microvascular network present at 5.5 weeks and all later times in both the $\mathrm{CP}$ and more or less throughout the villous tree, with connection between the two. Though at all times examined the majority of CD31+ or CD34+ cells were incorporated in the developing anastomosing vascular network, it was possible to pick out evidence of vasculogenic activity in the form of double blind-ended cords using whole mount staining (Supplemental Figures 2-4). Such sites were usually associated with the tips of growing villi. They were not observed to have any particular association with CD235+ foci, and indeed were seen in areas from which the latter were absent. They could be observed as late as 10 weeks.

CD31+ specks could be seen in CD235+ foci (Figure 5F) that did not contain organised CD31+ vascular structures, and lacked a discrete layer of CD31+ cells at the periphery. At 8 weeks (and to a lesser extent at 5 weeks), CD235+ cells could be seen tightly packed in CD31+ vessel channels adjacent to HAF (Figure 5C). However, CD235 staining was absent from most areas of the CD31+ villous vascular network. By 9 weeks packed CD235+ cells were detected extending farther into the developing vascular network. At 10 weeks CD235 $5^{\text {bright }} /$ CD31 $1^{\text {weak }}$ aggregates were uncommon and many more vascular elements contained CD235+ cells. Bright field examination confirmed that oxyhemoglobinpositive cells were spread extensively through vascular channels in the villous tree. 
Tightly packed immature cells in cleft-shaped HAF near to the trophoblastic surface were CD34positive (Figure 6A, 6 weeks), and many were also nestin-positive (Figure 6B, 6 weeks). However, CD34 and CD235a did not colocalise (Supplemental Fig 5). At connections into vascular channels, CD34 (Figure 6C, 5 weeks) and nestin (not shown) both segregate into endothelium, being absent from the rounded adherent luminal cells, while CD41 staining was present in non-endothelialised foci as well as in cells feeding into vascular channels (Supplemental Fig 6). Alpha smooth muscle actin (not shown) was found on some presumptive endothelial cells as well as on a scattered population of mesenchymal cells. FLK1 staining was found in presumptive endothelial cells but not in most luminal ones (Figure 6D, 5 weeks). Large rounded nucleated luminal cells, and rounded cells adherent to endothelium, were brachyury-positive up to at least 8 weeks, consistent with an early mesenchymal lineage (Figure 6E). Where gaps were present in the developing endothelium, brachyury-positive cells could be seen adhering to the tissue surface (Figure 6E). Very occasionally CD45+ cells were present in HAF (Figure 6F). CD68 recognised a prominent population of Hofbauer cells at all gestational ages. Though often found in adjacent areas of villous stroma (Figures 4F, 6G), and occasionally in open vessel spaces (Figure 4G), they were not seen amongst the cells in closepacked HAF.

\section{Discussion}

Almost all areas of extraembryonic mesenchyme examined in the 4-10 week period were richly endowed with CD31-positive cords and microvessels, even at the placental periphery, indicating that investment with vascular elements follows closely the outgrowth of new mesenchyme. It has never been delineated how late in gestation vasculogenesis (as opposed to angiogenesis) can occur; here we examined endothelial markers in whole mounted and serially sectioned specimens as late as 10 weeks and were able to discern sites where vasculogenesis appeared to be taking place. Inward growth from villous tips seems to be guided in a way that allows newly forming cords to join up with 
elements of the existing angiogenic network located more proximally to the $\mathrm{CP}$, possibly facilitated by Hofbauer cells which, as tissue macrophages, may promote the joining of tip-cells [16] by providing a bridge and mediating fusion [17]. Hofbauer cells are present in all early stages reported and are present in extraembryonic mesenchyme in advance of vascularisation [4, 5]. This suggests that both endothelial and macrophage lineages can arise de novo from mesenchymal precursors, though it remains possible that cells originating in the yolk sac might colonise the early placenta [18]. Hofbauer cells were widespread and randomly distributed in villous and chorionic plate tissues examined in the present study, however they were not observed amongst the close-packed cells in HAF. We therefore suggest that the macrophage is not a derivative of the primitive cells found in HAF. A majority of endothelial cells and pericytes [19] probably arise directly from primitive mesenchymal precursor cells; indeed placental mesenchymal stem cells from various times of gestation have been shown to have the capability to differentiate in vitro into endothelial cells [20]. However, based on the localisation studies herein, we suggest that a second minority population of endothelial cells arises within HAF, forming a peripheral layer that eventually encases the foci and joins them to the wider vascular network. Studies of embryonic stem cells have demonstrated the existence of a mesoderm-derived precursor for both mesenchymal stem and endothelial cells [21], and it will be interesting to see if such a cell can be isolated from human placenta. Lectin histochemistry has previously shown term endothelial cells to exhibit heterogeneity [22] as seen here in early pregnancy, and this may reflect differences in surface properties related to cell adhesion which may be important in release of erythroid cells into the lumen, and/or different developmental origins.

Early morphologists did not report hemangioblastic sites [2], possibly because if not promptly fixed, they become difficult to distinguish from red cells densely packed into vascular channels. Later higher-quality histological studies discerned these sites and described some of the phenotypic features of the constituent cells $[5,6]$. It has also become clear that mouse placenta is an important site of hematopoiesis [11]. The combination of bright field examination of fresh, unfixed, flat- 
mounted tissue, histochemistry of resin-embedded tissues fixed soon after delivery, and wholemount double immunofluorescence with antibodies to CD235a (erythroid lineage cells) and CD31, clearly identifies mesenchymally-located foci. Consistent CD235a positivity, together with the presence of cells with few organellar features and dense or condensing nuclear morphology identify them as predominantly sites of erythroid development, in keeping with the predominance of erythroid CFUs in placental cells cultured from early gestation tissue [9]. However there is evidence that CD235a can mark hematopoietic stem cells [23] and the presence of CD41/integrin allb suggests that primitive cells might be able to progress into other blood cell lineages. This has previously been suggested in mouse $[24,25]$, but midgestation placental CD41+ cells could not reconstitute definitive hematopoiesis [26], so further investigation is warranted in human. The details of erythroid maturation and its control are still to be worked out, but erythropoietin, a potent stimulator of erythroid lineage cells, is produced by trophoblast, and a paracrine interaction has been demonstrated in which blocking PDGF signalling leads to upregulation of EPO and an increased erythroid cell population in the mouse placenta [27]. The data are consistent with the idea that the most active sites of erythroid initiation and maturation in human are in crypts adjacent to the trophoblast basement membrane. Stromal (extravascular) erythroid cells were found to be associated with the later phases of HAF maturation at which cells start to dissociate, presumably for release into circulation. Such cells may be left behind after expulsion of the majority of cells from HAF into the vascular network, after which they are probably phagocytosed by Hofbauer cells, which are abundant in such areas. Some pyrenocytes were detected, and it has been suggested that Hofbauer cells may ingest nuclei extruded from red blood cells originating either in the yolk sac or placenta [28]. However we tend to the supposition that most cells released from HAF into the embryonic circulation are nucleated. these niches that retain the potential to produce endothelial (and probably other vascular) cells, 
they join up with the vascular tree, eventually becoming incorporated entirely at 9-11 weeks. They appear to open up progressively from the end proximal to the $\mathrm{CP}$, ie the developing fetal circulation. This sequence of events does not occur at one specific time of gestation - rather it depends on the location, and in all probability the relationship with the onset of blood flow in that area. That is, various patterns of HAF morphology coexist in different locations in the villous placenta throughout the period 4-11 weeks. Adherent, packed luminal cells characteristic of HAF seem to be cleared from the peripheral CP by 7 weeks, 2-3 weeks before they disappear from villi. Placentally resident stem cells present later in gestation clearly occupy a different niche, and indeed scattered stromal or perivascular CD45+ cells have been observed $[9,29]$.

The supply of fetal erythrocytes may well be initiated from the yolk sac, but this is closely followed by the $\mathrm{CP}$ and villous placenta, the aortic-gonadal-mesonephric region, the liver and finally the bone marrow. HAF contain cells expressing CD235a that also express high affinity fetal haemoglobin isoforms including $\mathrm{Hb} \zeta$ and $\mathrm{Hb} \varepsilon$ [28]. They are red on inspection after delivery, and hence bear oxygen, though this could result from exposure to atmospheric oxygen. However, they must bind oxygen tightly in the low partial pressure environment of the first trimester placenta. Initially not in communication with the fetal circulation, the foci probably act as a reservoir of oxygen, gradually releasing oxygen-charged erythrocytes into the fetal circulation. The presence of erythroid foci in the $\mathrm{CP}$ and proximal/central villous placenta - sites closest to the cord -- means that this drip-feed of cells can start from the earliest stages of fetal circulatory connection. Indeed in the rhesus macaque, intravillous circulation has been detected as early as 11 days after fertilisation [30]. We suggest more distal areas of the growing villous placenta are progressively incorporated. 
The authors report no conflicts of interest. The authors alone are responsible for the content and

writing of the paper.

\section{Acknowledgements}

We thank Dr Shawn Murphy, Rochester for advice and help with whole mount immunofluorescence,

Dr Caroline Dunk, Toronto for access to tissue, and Drs Anne Croy and Chandrakant Tayade (Kingston placenta workshop) for support for whole mount staining and imaging. SS was funded by a postgraduate studentship from the BBSRC.

[1] Hamilton WJ, Boyd JD and Mossman HW. Human Embryology 1945; Cambridge: Heffer.

[2] Boyd JD and Hamilton WJ. The Human Placenta 1970; Cambridge: Heffer.

[3] Aplin JD and Jones CJ. Human placental development. 2008; (Ed.) Aplin JD, Fazleabas, A., Glasser S.R., Giudice, L.C. London, U.K.: Informa Press.

[4] Dempsey EW. The development of capillaries in the villi of early human placentas. Am J Anat. 1972;134(2):221-37.

[5] Demir R, Kaufmann P, Castellucci M, Erbengi T and Kotowski A. Fetal vasculogenesis and angiogenesis in human placental villi. Acta Anat (Basel). 1989;136(3):190-203.

[6] Challier JC, Galtier M, Cortez A, Bintein T, Rabreau M and Uzan S. Immunocytological evidence for hematopoiesis in the early human placenta. Placenta. 2005;26(4):282-8.

[7] Pereda J, Monge JI and Niimi G. Two different pathways for the transport of primitive and definitive blood cells from the yolk sac to the embryo in humans. Microsc Res Tech. 2010;73(8):8039.

[8] Robin C, Bollerot K, Mendes S, Haak E, Crisan M, Cerisoli F, Lauw I, Kaimakis P, Jorna R, Vermeulen M, Kayser M, van der Linden R, Imanirad P, Verstegen M, Nawaz-Yousaf H, Papazian N, Steegers $\mathrm{E}$, Cupedo $T$ and Dzierzak E. Human placenta is a potent hematopoietic niche containing hematopoietic stem and progenitor cells throughout development. Cell stem cell. 2009;5(4):385-95. [9] Barcena A, Kapidzic M, Muench MO, Gormley M, Scott MA, Weier JF, Ferlatte C and Fisher SJ. The human placenta is a hematopoietic organ during the embryonic and fetal periods of development. Dev Biol. 2009;327(1):24-33.

[10] Gekas C, Dieterlen-Lievre F, Orkin SH and Mikkola HK. The placenta is a niche for hematopoietic stem cells. Developmental cell. 2005;8(3):365-75.

[11] Gekas C, Rhodes KE, Van Handel B, Chhabra A, Ueno M and Mikkola HK. Hematopoietic stem cell development in the placenta. Int J Dev Biol. 2010;54(6-7):1089-98.

340 [12] Bushway ME, Gerber SA, Fenton BM, Miller RK, Lord EM and Murphy SP. Morphological and 341 phenotypic analyses of the human placenta using whole mount immunofluorescence. Biology of 342 reproduction. 2014;90(5):110. 

hemomonochorial placentae from five widely separated species of mammal: is there evidence for convergent evolution? Cells, tissues, organs. 2007;185(4):269-84.

[14] Jones CJ, Mosley SM, Jeffrey IJ and Stoddart RW. Elimination of the non-specific binding of avidin to tissue sections. The Histochemical journal. 1987;19(5):264-8.

[15] Zhang EG, Burton GJ, Smith SK and Charnock-Jones DS. Placental vessel adaptation during gestation and to high altitude: changes in diameter and perivascular cell coverage. Placenta. 2002;23(10):751-62.

[16] Fantin A, Vieira JM, Gestri G, Denti L, Schwarz Q, Prykhozhij S, Peri F, Wilson SW and Ruhrberg C. Tissue macrophages act as cellular chaperones for vascular anastomosis downstream of VEGFmediated endothelial tip cell induction. Blood. 2010;116(5):829-40.

[17] Schmidt T and Carmeliet P. Blood-vessel formation: Bridges that guide and unite. Nature. 2010;465(7299):697-9.

[18] Gomez Perdiguero E, Klapproth K, Schulz C, Busch K, Azzoni E, Crozet L, Garner H, Trouillet C, de Bruijn MF, Geissmann F and Rodewald HR. Tissue-resident macrophages originate from yolk-sacderived erythro-myeloid progenitors. Nature. 2015;518(7540):547-51.

[19] Gerhardt $\mathrm{H}$ and Betsholtz C. Endothelial-pericyte interactions in angiogenesis. Cell and tissue research. 2003;314(1):15-23.

[20] Chen CP, Liu SH, Huang JP, Aplin JD, Wu YH, Chen PC, Hu CS, Ko CC, Lee MY and Chen CY. Engraftment potential of human placenta-derived mesenchymal stem cells after in utero transplantation in rats. Hum Reprod. 2009;24(1):154-65.

[21] Vodyanik MA, Yu J, Zhang X, Tian S, Stewart R, Thomson JA and Slukvin, II. A mesoderm-derived precursor for mesenchymal stem and endothelial cells. Cell stem cell. 2010;7(6):718-29.

[22] Lang I, Hahn T, Dohr G, Skofitsch G and Desoye G. Heterogeneous histochemical reaction pattern of the lectin Bandeiraea (Griffonia) simplicifolia with blood vessels of human full-term placenta. Cell and tissue research. 1994;278(3):433-8.

[23] Sturgeon CM, Ditadi A, Awong G, Kennedy M and Keller G. Wnt signaling controls the specification of definitive and primitive hematopoiesis from human pluripotent stem cells. Nature biotechnology. 2014;32(6):554-61.

[24] Mikkola HK, Fujiwara Y, Schlaeger TM, Traver D and Orkin SH. Expression of CD41 marks the initiation of definitive hematopoiesis in the mouse embryo. Blood. 2003;101(2):508-16.

[25] Rhodes KE, Gekas C, Wang Y, Lux CT, Francis CS, Chan DN, Conway S, Orkin SH, Yoder MC and Mikkola HK. The emergence of hematopoietic stem cells is initiated in the placental vasculature in the absence of circulation. Cell stem cell. 2008;2(3):252-63.

[26] Robin C, Ottersbach K, Boisset JC, Oziemlak A and Dzierzak E. CD41 is developmentally regulated and differentially expressed on mouse hematopoietic stem cells. Blood. 2011;117(19):5088-91.

[27] Chhabra A, Lechner AJ, Ueno M, Acharya A, Van Handel B, Wang Y, Iruela-Arispe ML, Tallquist $\mathrm{MD}$ and Mikkola HK. Trophoblasts regulate the placental hematopoietic niche through PDGF-B signaling. Developmental cell. 2012;22(3):651-9.

[28] Van Handel B, Prashad SL, Hassanzadeh-Kiabi N, Huang A, Magnusson M, Atanassova B, Chen A, Hamalainen El and Mikkola HK. The first trimester human placenta is a site for terminal maturation of primitive erythroid cells. Blood. 2010;116(17):3321-30.

[29] Serikov V, Hounshell C, Larkin S, Green W, Ikeda H, Walters MC and Kuypers FA. Human term placenta as a source of hematopoietic cells. Exp Biol Med (Maywood). 2009;234(7):813-23.

[30] Keator CS, Lindner JR, Belcik JT, Bishop CV and Slayden OD. Contrast-enhanced ultrasound reveals real-time spatial changes in vascular perfusion during early implantation in the macaque uterus. Fertility and sterility. 2011;95(4):1316-21 e1-3. 


\section{Figure legends}

Fig 1 Flat-mounted fresh first trimester villi. Note that bulbulotubal structures rich in hemoglobin extend inwards from sites immediately beneath the trophoblast. They are absent from some villi, for example the left hand branch in B. They connect to presumptive channels that appear to lack hemoglobin. Details of channel systems in A and B are shown in C and D respectively. Scale bars: A, $25 \mu \mathrm{m} ; \mathrm{B}, 50 \mu \mathrm{m} ; \mathrm{C}, 15 \mu \mathrm{m} ; \mathrm{D}, 25 \mu \mathrm{m}$.

Fig 2 Hemangioblastic foci (HAF) are readily identified in histological sections at (A) 4 and (B) 6 weeks (arrows), and a simple empty small vessel profile can be seen in a villus at 6 weeks (C, asterisk). A is an archival specimen (H710) from the collection at the Centre for Trophoblast Research, Cambridge; the histological stain is unknown. B and $C$ are semithin resin sections stained with Toluidine blue. Note the elongated HAF extending from the edge towards the centre of the villous mesenchyme. The simple vascular channel shown in $C$ is from a field adjacent to $B$. Scale bars: $A, 40 \mu m$; $B \& C$, $5 \mu \mathrm{m}$.

Fig 3 Histology and lectin histochemistry of placenta and yolk sac reveals developing erythroid and endothelial cells in HAF. (A) Several HAF profiles visible in a Toluidine blue-stained villus at 8 weeks. (B) At higher magnification, thin cells are visible at the periphery of a HAF. (C) Solanum tuberosum agglutinin (STA) staining of an adjacent section reveals various degrees of differentiation in the developing erythroid lineage, as well as presumptive endothelium. (D) Archival specimen (H710; $4 \mathrm{~mm}$ CRL; Gomori's reticulin stain with neutral red counterstain) from approximately 4 weeks, revealing that the microfibrillar matrix around developing $\operatorname{HAF}\left({ }^{*}\right)$ is discontinuous. $(E, F)$ Combining Ulex europaeus-1 agglutinin (UEA-1) staining with a hematoxylin counterstain reveals a discontinuous endothelium (8 weeks). (G,H, I) Yolk sac ( 6 weeks) stained with UEA-1 and counterstained with hematoxylin, demonstrating features of endothelial and erythroid development similar to those seen in placenta at the same stage. (J) Phytolacca americana agglutinin (PAA) 
binding to a 4 week placental vessel $\left({ }^{*}\right)$ demonstrates endothelial cell heterogeneity. Scale bars: A, $50 \mu \mathrm{m} ; \mathrm{B}, \mathrm{C}$ and J, $25 \mu \mathrm{m} ; \mathrm{D}, 15 \mu \mathrm{m} ; \mathrm{E} \& \mathrm{~F}, 10 \mu \mathrm{m} ; \mathrm{G}, \mathrm{H}, \mathrm{I}, 5 \mu \mathrm{m}$.

Fig 4 Histology of CP and stem villi, illustrating opening of vascular luminal spaces and release of cells from different parts of the placenta, 6-7 weeks. (A) A central area in the CP at about 6 weeks (CTR specimen H33, CRL 10mm) shows large vessels opening up. Note that in an adjacent stem villus, cell displacement from a putative HAF is occurring proximally to the CP (arrow). Further away from the stem villus-CP junction, putative HAF are densely packed with cells (arrowheads). However fixation quality limits the interpretation. (B) This shows central CP and stem villus, also at 6 weeks; the arrows point to small open capillaries in the $\mathrm{CP}$, while the arrowhead locates a vessel in a stem villus from which cells are being displaced, note again the initiation of displacement is from the direction of the CP. (C) Peripheral CP at 6 weeks showing an elongated HAF containing tightly packed cells (arrows) near to the trophoblast epithelium; (D) peripheral villus at 7 weeks showing a HAF containing closely packed cells at various stages of differentiation; $(E)$ central proximal villus at 7 weeks showing a large vessel with open lumen containing cells including differentiated erythrocytes. (A) Archival pregnancy hysterectomy specimens, presumed H\&E. (F,G) Two areas from an 8 week placenta showing erythroid cells in vascular spaces and adjacent areas of stroma. In F, arrows highlight Hofbauer cells in the stroma and in a vessel. In G, arrows identify pyrenocytes (red cell nuclei) both in stroma and vessels. However most erythroid cells in both locations are nucleated. Note that vascular endothelium is thin and discontinuous in both fields. (B-G) Toluidine bluestained semithin resin sections. Scale bars: A, $125 \mu \mathrm{m} ; \mathrm{B}, 25 \mu \mathrm{m} ; \mathrm{C}, 10 \mu \mathrm{m} ; \mathrm{D}, 20 \mu \mathrm{m} ; \mathrm{E}-\mathrm{G}, 25 \mu \mathrm{m}$.

Fig 5 Immunofluorescence of whole-mounted first trimester villous tissue using antibodies to CD235a and CD31. Examples from 5.5 weeks $(A-C)$ and 8 weeks (D-F). A and E show CD235a, while B

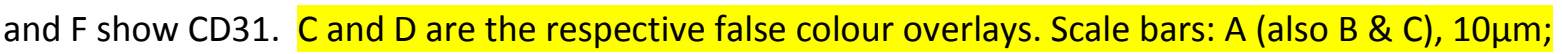
$\mathrm{D}$ (also $\mathrm{E} \& \mathrm{~F}$ ), $25 \mu \mathrm{m}$. In C a developing vessel is shown containing tightly packed CD235a-positive cells, and a discontinuous endothelium (dotted lines show gaps, while asterisks mark endothelialised 
segments). In D a HAF (asterisk) contains many CD235a-positive cells along with traces of CD31

immunoreactivity, and is immediately adjacent to a developing network of CD31+ cords and vessels. CD235a+ cells appear to be forming into channel-like structures (asterisk in E) but these have not yet acquired an endothelium, nor have they become incorporated into the adjacent CD31+ vascular network.

Fig 6 Immunohistochemistry of lineage markers in 4-8 week villi. Antigens and gestational ages are shown. Aand B are adjacent sections. CD34 (A, C), nestin (B) and FLK 1 (D) are present in endothelial cells of the HAFs (arrows), with FLK 1 also being found in cytotrophoblast cells. Brachyury positive cells are present in HAFs (E), some of which adhere to the wall of the vessel (arrow). In F, CD45 is expressed by a leucoyte in a HAF (arrows) and in G stromal macrophages are stained (arrow). $\mathrm{Tr}=$ trophoblast. Scale bars: A (also B-F), $25 \mu \mathrm{m} ; \mathrm{G}, 75 \mu \mathrm{m}$.

Supplemental Fig 1. Serial sections of Toluidine blue-stained semithin sections of a 6 week villus. The red rectangle identifies a group of cells that shows 4 nuclei in the first image, but another nucleus appears in the third section. The circle in image 9 surrounds an apparently anuclear cell that is revealed in image 10 as containing a small pyknotic nucleus that has been cut through by image 11, while the triangle in image 11 around an anuclear profile contains a nucleus in image 12 . Scale bar: $10 \mu \mathrm{m}$. Contrast has been increased to maximise the clarity of nuclear profiles, as a result of which the surrounding stroma appears bleached.

Supplemental Fig 2. A vasculogenic site near the tip of a distal villus at 5 weeks. This is a conventional fluorescence image of a flat mounted specimen stained with CD31, with all the vascular elements visible, though not all are in focus. Note that cords are extending from an area at right, which is near the villus tip, towards a more proximal, well-vascularised angiogenic zone at left. Scale bar: $15 \mu \mathrm{m}$. 
Supplemental Fig 3. A series of fluorescence planes from a 5 week villus whole mount preparation stained with CD34 to localise endothelial cells in vasculogenic sites, assembled into a movie (approximately 20 seconds).

Supplemental Fig 4. Stills from the Z-stack series in Fig 3. A: 3 seconds. CD34 positive vessel (arrow) positioned immediately below the cytotrophoblast layer (CT) though which the imaging plane passes. B: 7 seconds; Example of a blind-ending vessel (arrow.) C: 13 seconds. As the series moves deeper into the villus small CD34 positive structures (circled) can be identified that are physically isolated from, and do not join with, surrounding vessels. A vessel appears to branch in the direction of the trophoblast (arrow). CD34 (green), PI (red). Scale bar: 50 $\mu$ m (all images to same scale).

Supplemental Fig 5. Whole mount immunofluorescence showing CD235a (green) and CD34 (red). Small HAF at 8 and 10 weeks show both CD34 and CD235a positivity but no colocalisation is detected. Note that CD34 also marks adjacent vascular networks.

Supplemental Fig 6. Whole mount immunostaining with CD41/integrin allb (green) and CD31 (red). The 5, 7 and 10 week images show CD41 in the centre panel and CD31 in the right panel, with DAPI added to the colour images. DAPI marks trophoblast most effectively. The boxed area at 5 weeks is shown in two focal planes. Asterisks mark non-endothelialised HAFs at 6 and 7 weeks. At 5 and 10 weeks most CD41+ cells are enclosed within vascular structures though the endothelium is not continuous (eg white dotted line at $5 \mathrm{w}$, top left). 
Figure 1
Click here to download Figure: Fig 1.pptx

Fig 1. Flat-mounted fresh first trimester villi.
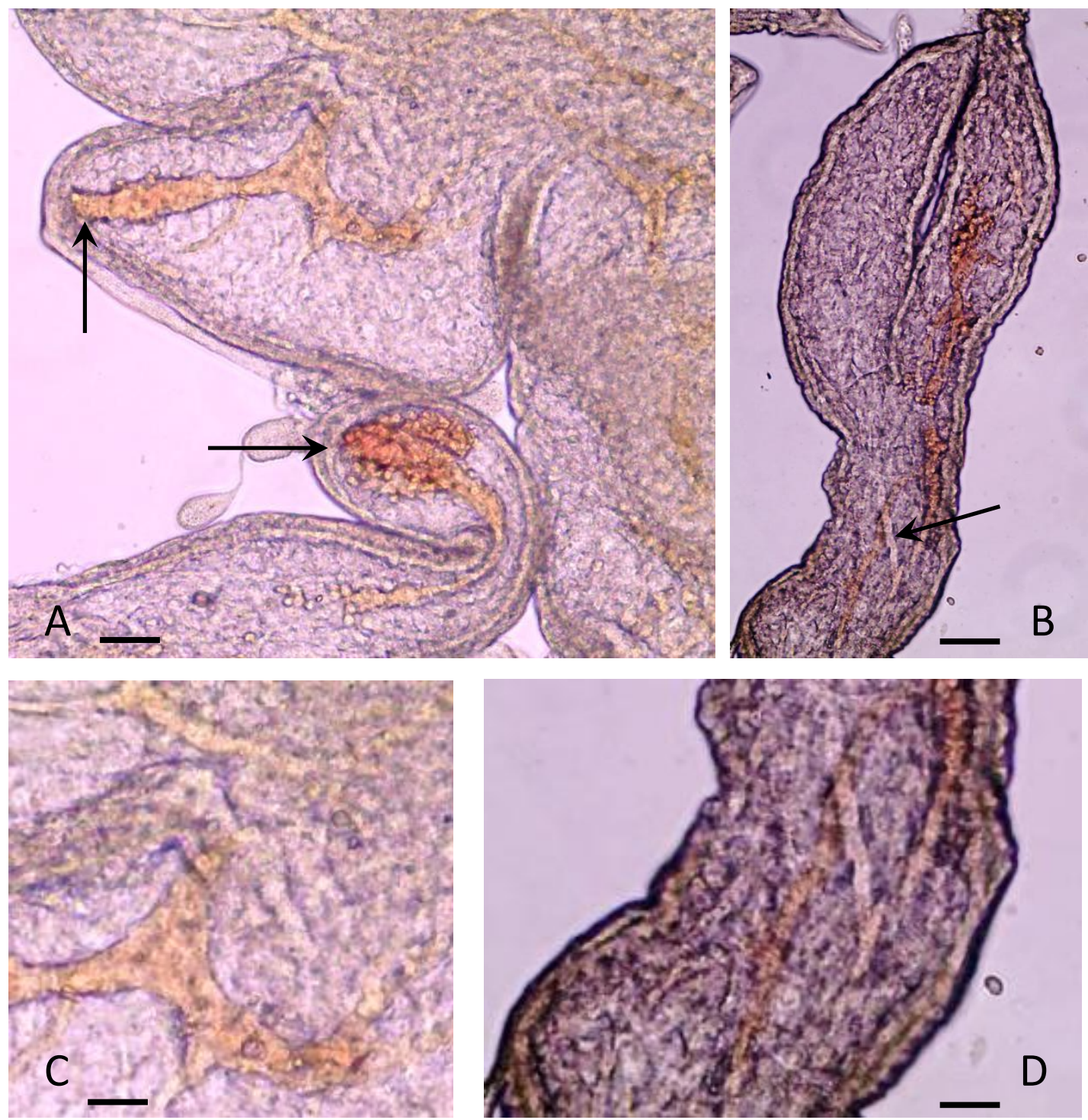
Figure 2
Click here to download Figure: Fig 2.pptx

Fig 2. Hemangioblastic foci (HAF) in first trimester villi.

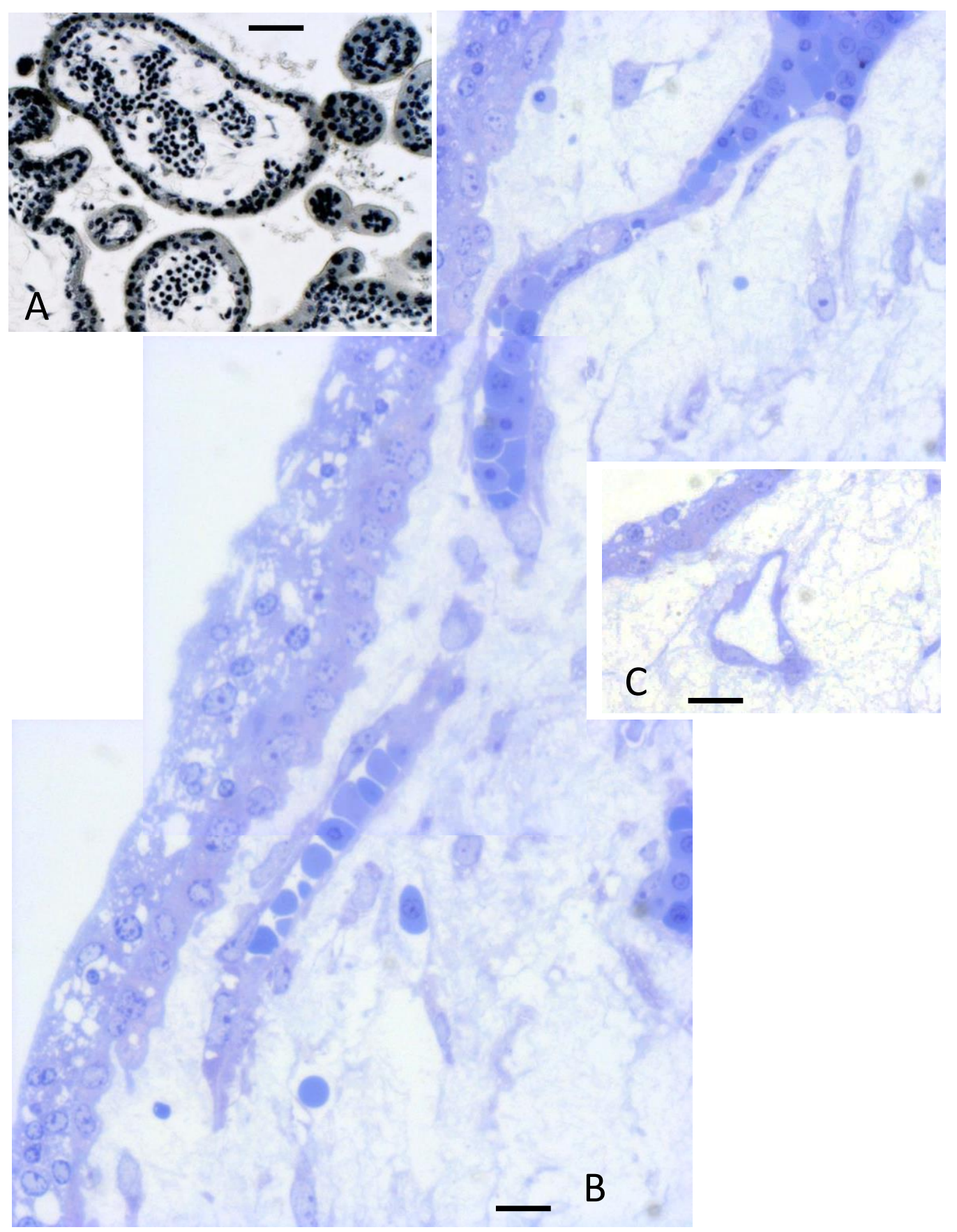


Click here to download Figure: Fig 3 (3).pptx

Fig 3. Lectin histochemistry of placenta and yolk sac.

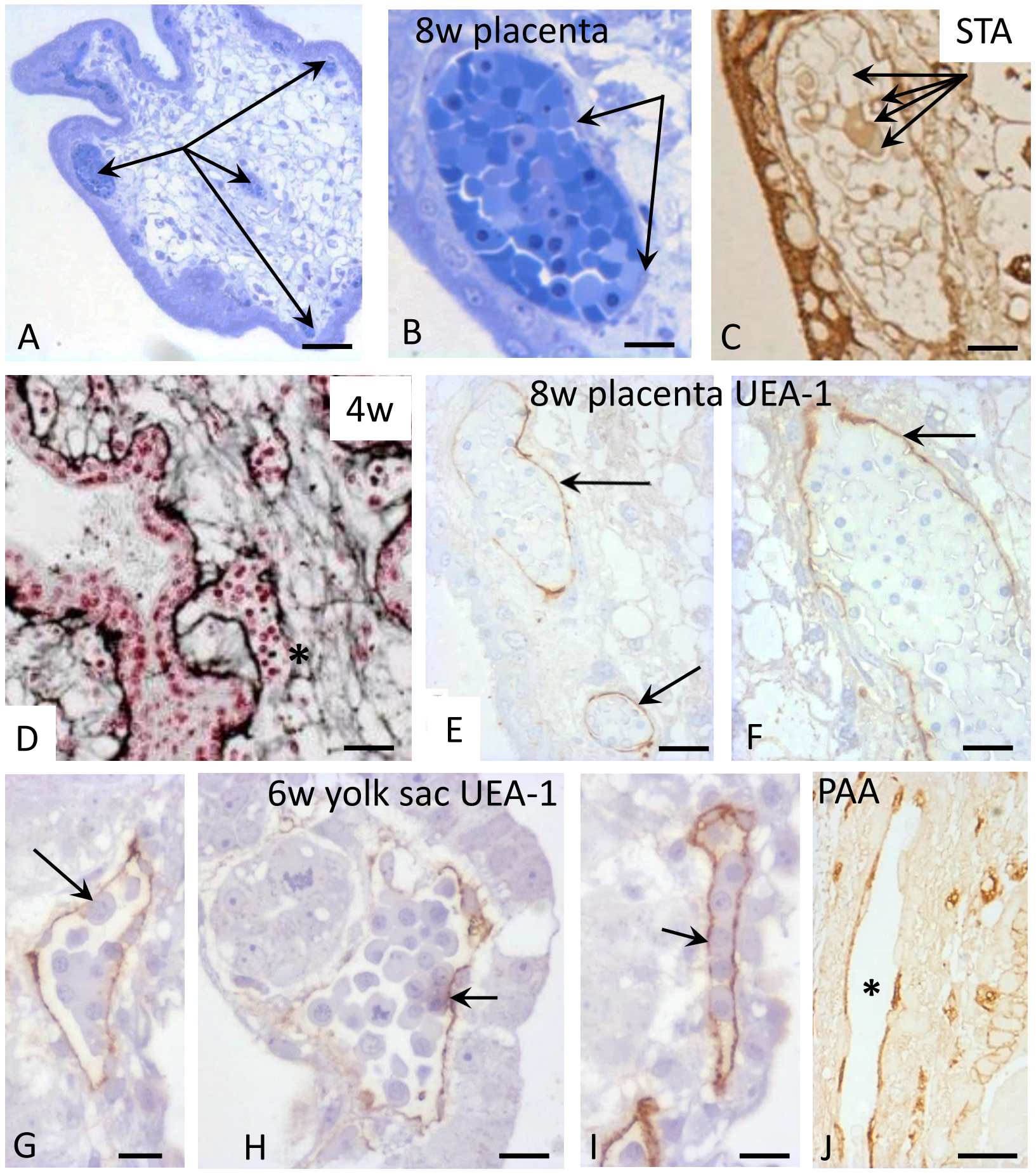


Figure 4
Click here to download Figure: Fig 4.pptx

Fig 4. Histology of $\mathrm{CP}$ and stem villi in different parts of the placenta.

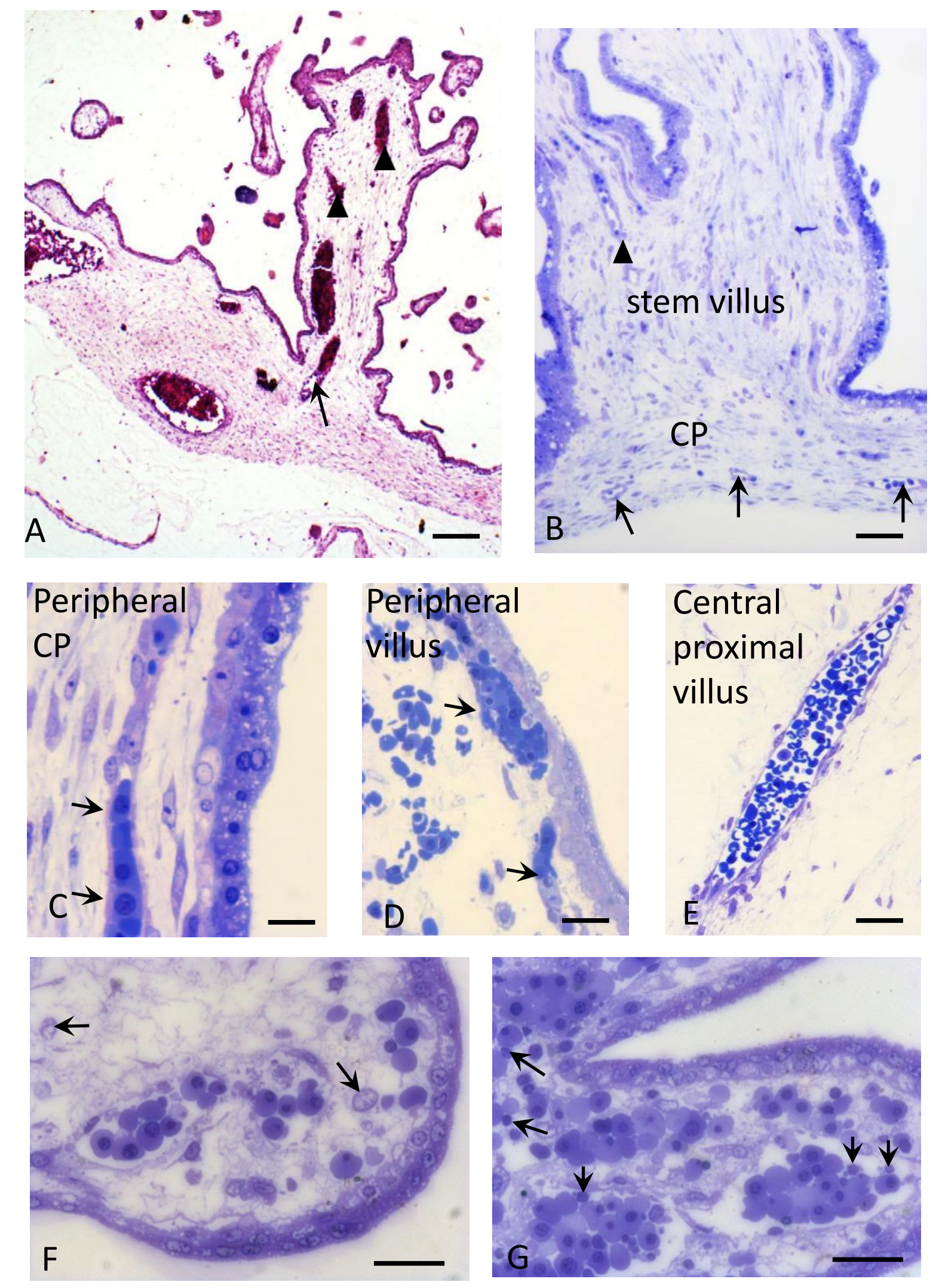


Figure 5
Click here to download Figure: Fig 5.pptx

Fig 5. Whole mount immunofluorescence of first trimester placental villi.
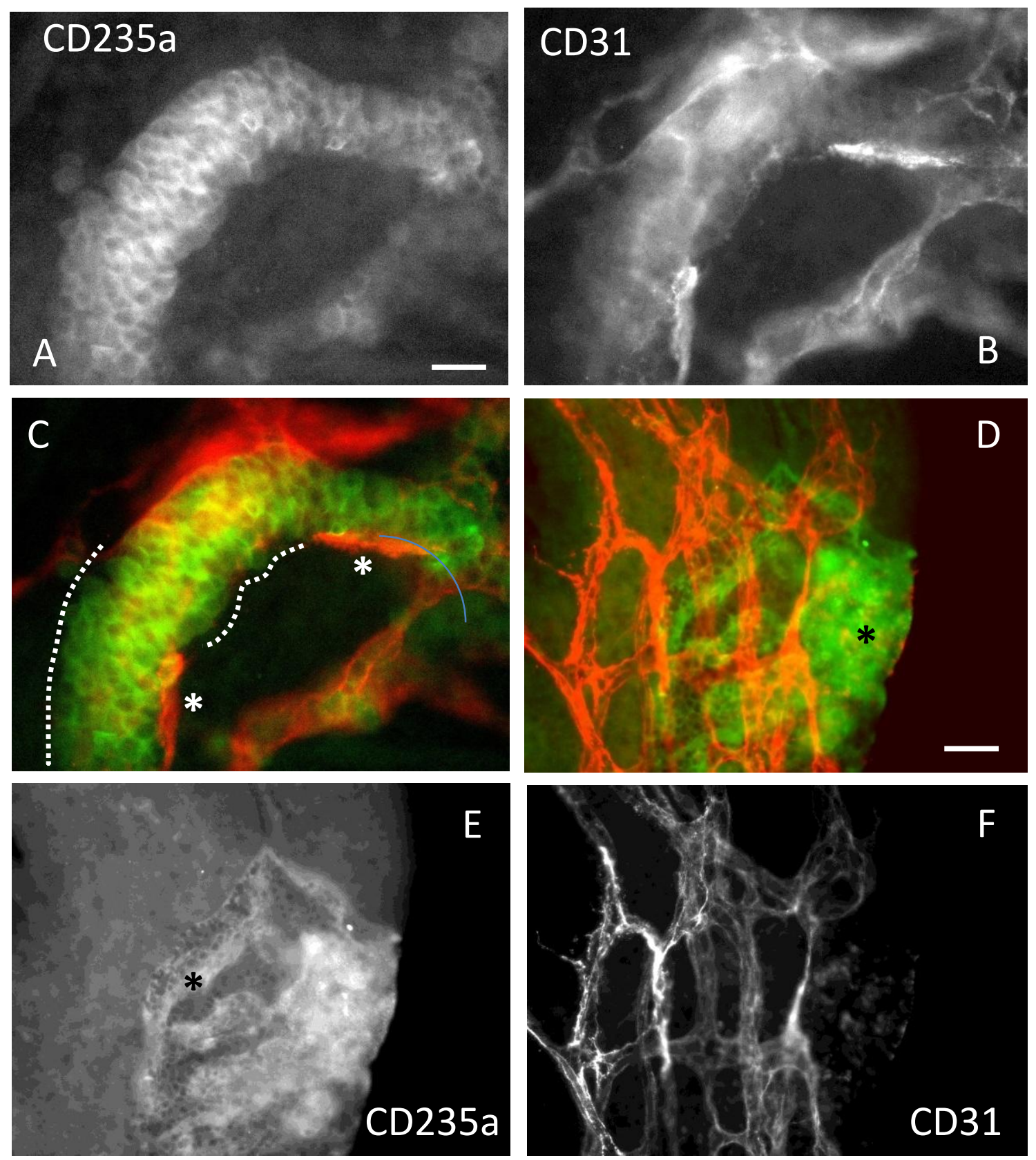
Figure 6
Click here to download Figure: Fig 6.pptx

Fig 6. Immunohistochemical characterisation of lineage markers in cells in HAF.

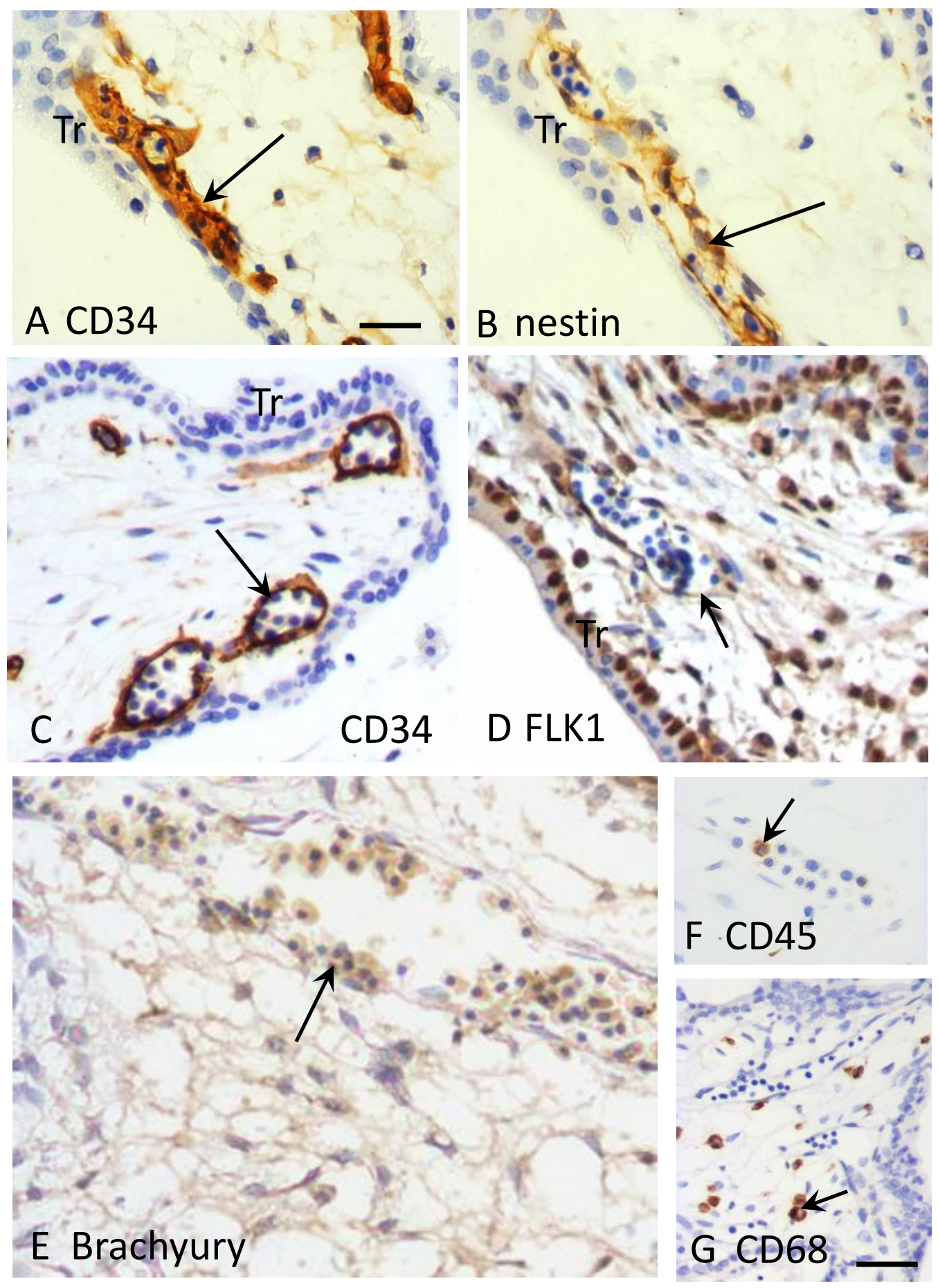


Supplemental Flg 1
Click here to download Supplementary File: Supplem Fig 1.pptx

ton

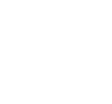

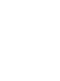

(n)

(n)

(n) (1) (1) (1)

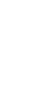
(1) (1) (20) (1)

(1) (1) (1) (1) (1) (1)

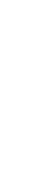

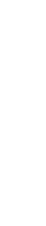
. . . . . . 列

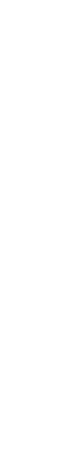
.

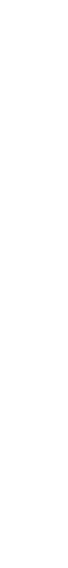

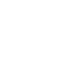

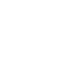

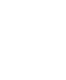

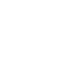

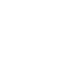

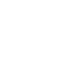

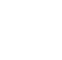


Supplemental Flg 2
Click here to downlo

Click here to download Supplementary File: Supplem Fig 2.pptx

Click here to download Supplementary File: Supplem Fig 2.pptx

(1)

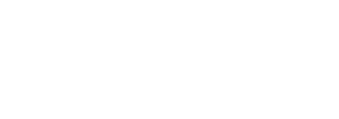

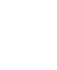
.

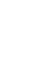
(

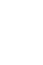

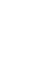

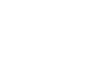
(1) (1) (1) (1) (1) (1) (1) (1) (1) (1) (1) (1) (1) (1) (1) (1) (1) (1)

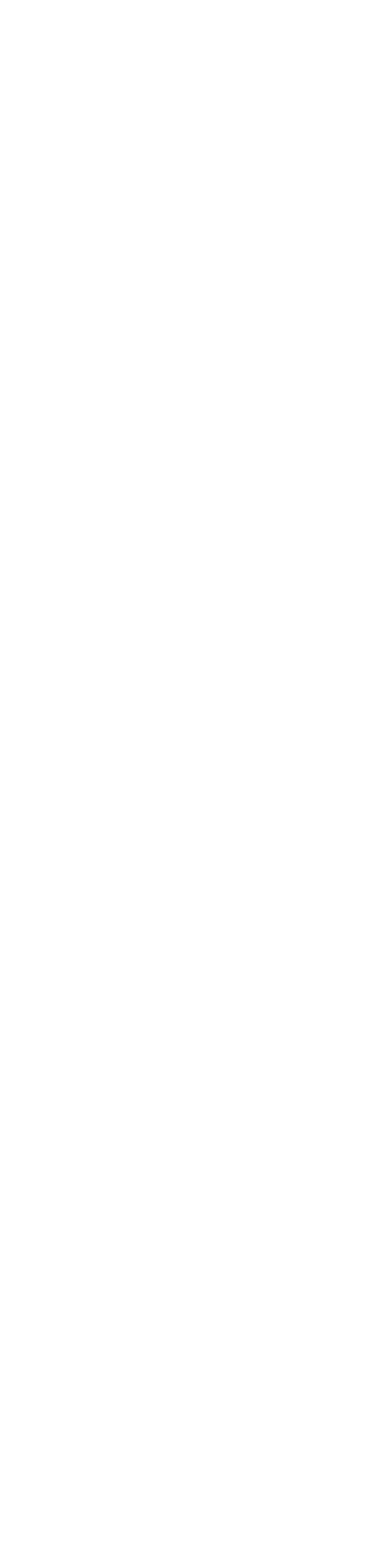

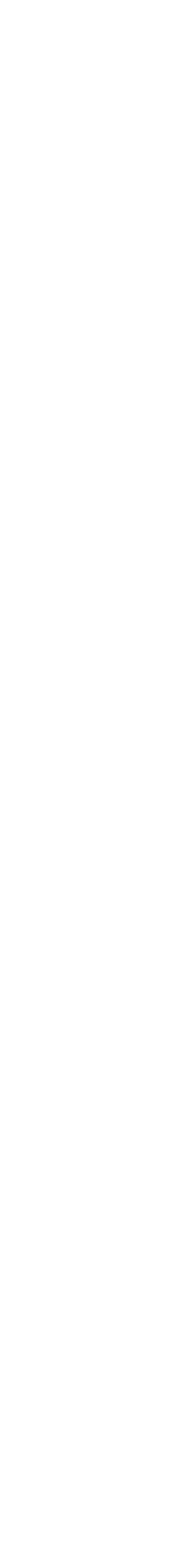


Supplemental Flg 3
Click here to download Supplementary File: Supplem Fig 3.pptx

Supplemental Flg 3
Click here to download Supplementary File: Supplem Fig 3.pptx

Click here to download Supplementary File: Supplem Fig 3 pptx

. 
Supplemental Flg 4
Click here to download Supplementary File: Supplem Fig 4.pptx

Supplemental Flg 4
Click here to download Supplementary File: Supplem Fig 4.pptx

Click here to download Supplementary File: Supplem Fig 4.pptx

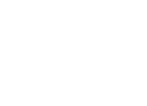


Supplemental Flg 5
Click here to download Supplementary File: Supplem Fig 5.pptx

Supplemental Flg 5
Click here to download Supplementary File: Supplem Fig 5.pptx

Click here to download Supplementary File: Supplem Fig 5 .pptx

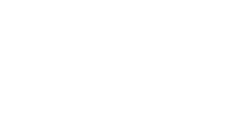
(1)

(1)

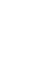
(1) (1)

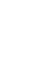
(1) (1) (1) (1) . . . . . . . . . . . . . . . . 
Click here to download Supplementary File: Supplem Fig 6.pptx

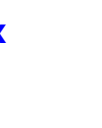

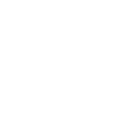

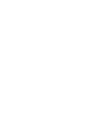

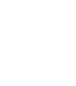

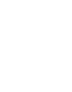

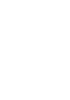

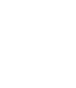

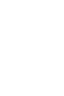

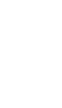
.

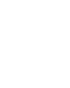

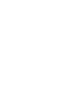

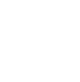

